\title{
HYPERSOMNIA IN DYSTROPHIA MYOTONICA
}

\section{BY}

\section{J. C. PHEMISTER and J. M. SMALL}

\author{
From the Department of Neurology, The London Hospital
}

We have been interested to note the occurrence of marked hypersomnia and somnolence in four patients suffering from dystrophia myotonica. Somnolence has been described before in this condition (Rohrer, 1916; Thomasen 1948) but the association has not had much emphasis and cannot be said to be widely known. Three of our patients were known myotonic subjects in whom hypersomnia was a troublesome incidental complaint, but the fourth came complaining of fainting attacks and an unmanageable liability to oversleep, and it was only then that an unrecognized dystrophia myotonica came to light.

\section{Case Reports}

Case 1.-M.J., a man aged 30, was an insurance broker. Dystrophia myotonica had been diagnosed 13 years previously. When on holiday fly-fishing, he found an unusual difficulty in striking and a medical acquaintance at the fishing hotel suggested the diagnosis, which was later confirmed by Sir Russell Brain. At this time he already presented a typical picture, with frontal baldness, a myopathic facies, wasting of the sternomastoid muscles, and testicular atrophy. Muscle wasting was general, particularly affecting the forearms and hands.

Family History.-His maternal grandfather had bilateral cataract. His father died in an accident at the age of 59 but had shown no sign of the disorder. An elder brother had early baldness, but no muscle disturbance and no cataract. A younger brother was found to have fairly typical dystrophia myotonica, but had no history of any disturbance of sleep.

Past History.-He had had pneumonia at the age of 12 months and had been "chesty" all his life.

He was given quinidine at first, with moderate improvement. In 1955 he was transferred to procaine amide and responded very well indeed on a dosage of between 4 and $6 \mathrm{~g}$. a day. In January, 1959, he was referred again to Sir Russell Brain with the complaint of increasing lethargy, and was admitted to the London Hospital. His mother, with whom he lived, had become concerned at his periodic liability to sleep on for as long as 48 hours at a time. During a period of several months he might sleep from a Friday evening until the Monday morning. He would be normally rousable, but would resent being wakened and would at once turn over and go back to sleep. His sleep was restless. On the Monday morning he would wake normally and go to work as usual. Apart from this hypersomnia, he was at all times easily apt to go to sleep although he never slept when travelling. He had had no disturbance resembling cataplexy.

On examination, his characteristic myotonic appearance was as described above. He was an intelligent man, alert, and cooperative in conversation. He had a myotonic dysarthria, myotonia of the grip, and myotonia on percussion of the thenar muscles and of the tongue. There was no abnormality of the nervous system apart from the changes to be expected in dystrophia myotonica. There were no abnormal signs in the chest, but the chest expansion was only $\frac{3}{4}$ in.

The blood picture showed no abnormality. A radiograph of the chest showed bilateral basal bronchiectasis. A radiograph of the skull was normal. An oral glucose tolerance test was normal. Serum sodium and potassium were normal. Radio-active iodine uptake was normal. The 17- ketosteroid and 17-ketogenic steroid excretions were normal, with a normal increase in output after the administration of 60 units of A.C.T.H. twice daily for three days. An electromyogram gave characteristic findings of myotonia.

While he was in bed in the ward, a remarkable immobility of posture was noted. At all times, movement was of restricted excursion so that he had superficially a rather Parkinsonian appearance. He was not drowsy but drifted easily into a light sleep. When the administration of procaine amide was stopped for a time there was a disabling return of the myotonia without evident change in his liability to go off to sleep.

Case 2.-M.C., a woman aged 23, a tailoress, was unmarried. In February, 1959, she began to have fainting attacks. These were liable to occur first thing in the morning when she rose from bed, or when she had been sitting for any length of time in the same position at work. She might have a light-headed feeling without actually losing consciousness, but usually after brief light-headedness she would fall to the ground unconscious without involuntary movement, tonguebiting or incontinence. She would recover consciousness within a matter of minutes and be well apart from slight frontal headache. She knew of no precipitant of the attacks.

For as long as she could remember, she had gone to bed at six o'clock in the evening and slept until it was time to get up to go to work in the morning: she would 
have to be shaken awake at seven o'clock. Periodically, she has had spells lasting a few months at a time when she would remain in bed asleep over the entire weekend. "When my mother tried to wake me I would just turn over and go off to sleep again." Her mother described her as being very restless during her sleep.

To direct questioning, she admitted occasional difficulty in releasing her grip when ironing, but she had no complaint referrable to the myotonia.

Family History.-She is the eldest of five sisters, who are all well. The father is well, the mother a migraine subject. There is no family history of epilepsy, muscle disease, or cataract.

Past History.-She had scarlet fever at the age of 11 . Recently, a chalazion had been removed from the right lower lid.

On examination, she was a rather poorly cooperative patient of less than average intelligence. She had a myopathic facies with bilateral ptosis, and general muscle wasting and weakness, greater distally. The sternomastoid muscles were only thin straps. There was myotonia of the grip, and on percussion, of the tongue. Tendon responses were all brisk: she had long fingers and a high arched palate, and normal distribution of body hair.

The blood picture was normal, and radiographs of the chest and skull were normal. Serum electrolytes were normal. An electromyogram showed a typical myotonic picture. In the E.E.G. there was no real alpha rhythm, but a mixture of low voltage fast and irregular theta activities diffusely and bilaterally. A little paroxysmal fast activity was present symmetrically in the fronto-temporal regions. Overbreathing produced very little effect. Photic stimulation evoked a good bilateral following response. Ocular compression produced no response.

When in the ward, it was seen that she was always very apt to drop off to sleep though she was easily rousable. She had no episodes of loss of consciousness. She was given procaine amide, $4 \mathrm{~g}$. daily, and with this there was a great subjective improvement and the myotonia disappeared to clinical testing. The somnolence was unaffected.

Case 3.-J.C., a schoolgirl, aged 16, had had difficulty in relaxing her grip since the age of 11. She falls off to sleep very easily, especially when travelling by car or bus, and has always had difficulty in getting up in the morning. She is inclined to sleep always, and never goes to bed later than eight o'clock. Her sister, who sleeps with her, complains of her restlessness at night. She has never had fainting turns, or anything resembling cataplexy. There was nothing relevant in her past history, and her father, mother, and sister are well. There is no family history of muscle disease or cataract.

On examination, there was some wasting of the sternomastoids and of the distal musculature of the upper limbs, and myotonia to percussion of the tongue and of the thenar muscles. She is slightly built and sexually underdeveloped. The nervous system was normal except for dull tendon responses.
The blood picture was normal. Radiographs of the $\underset{\mathbb{D}}{\not}$ chest and skull were normal. Serum electrolytes were normal. An electromyogram showed the typical changes of myotonia.

Case 4.-J.T., a man aged 38, a clerical worker, at $\bigcirc$ the age of 27 first noticed a nasal quality to his voice. Soon after this, he began to have nasal regurgitation of $\stackrel{?}{=}$ fluids. His face became thinner and he developed weakness of the hands. Dystrophia myotonica was first. diagnosed in 1952. At this time he had a myopathic $\vec{F}$ facies and wasting of the sternomastoid muscles, but no $\stackrel{\text { ? }}{\rightarrow}$ frontal baldness and no testicular atrophy. The weakness $\bar{C}$ increased steadily and his condition was little influenced $\underline{\underline{G}}$ by quinidine or procaine amide. In May, 1959, he began $\overline{\bar{c}}$ for the first time to have attacks in which his legs "just $\mathbb{\Phi}$ gave way". He was found at this time to be taking large doses of methedrine to counter the tendency to go to $\mathrm{s}$ sleep which had troubled him always. He said that for $\overrightarrow{0}$ as long as he could remember he had had a troublesome liability to go off to sleep during the day, and had had to $\vec{\omega}$ go to bed early and yet be shaken awake in the morning.

Past History.-He had been rejected for the Army at the age of 20 because of "heart trouble".

Family History.-One brother, six years younger, has dystrophia myotonica but not the same tendency to ? sleepiness. His father and mother, both aged 72 , are $\vec{\omega}$ well. There is no other family history of muscle disease, cataract, epilepsy, or heart disease.

On examination, he was an intelligent, cooperatie patient, with a myopathic facies and wasted sternomastorid muscles. He had an indistinct voice with a nasal qualit.\$. There was weakness and wasting of the muscles generalfy. $\overrightarrow{0}$ but particularly distally in the limbs. Tendon respons were dull in the arms, absent in the legs. No other abnormality was found in the nervous system. He had early bilateral cataracts, typical of dystrophia myotonica, and two chalazions on the right upper eye-lid and one on the left lower lid. Both femoral pulses were impalpable. He had no frontal baldness; the testes were normal.

The blood picture was normal. A radiograph of the chest showed the appearances typical of coarctation of $\overline{0}$ the aorta, and an E.C.G. a PR interval of 0.24 second, and a QRS complex widened to $0 \cdot 10$ second. An electromyogram showed the typical changes of myotonia.

\section{Comment}

The similarity in the accounts of the hypersomnia $\frac{0}{\circ}$ given by the first two patients is striking: both have on occasion slept out the entire week-end. All four $\delta$ have a tendency to fall asleep when their attention is not held, and this might suggest that the disorder is 0 best considered as a narcolepsy. There are a number of points against this. No patient had experienced episodes which could fairly be called cataplectic. None of them described the waves of irresistible $N$ sleep to which many narcoleptics are subject: they N just went to sleep. Patients with troublesome N narcolepsy during the day usually sleep badly at ${ }^{\omega}$ night and wake frequently. These patients, though 
admittedly restless, slept soundly. The term narcolepsy is better avoided here, and the condition spoken of as a hypersomnia.

The first patient had been taking quite large doses of procaine amide when the disturbance of sleep first appeared, and it was questioned whether the drug might be a cause. However, neither drowsiness nor a tendency to sleep have been reported after its use, and on the contrary it is liable to cause insomnia. Later, similar hypersomnia was noted in patients who had never received the drug.

The apathy and lack of interest shown by these patients was very marked, and it was difficult not to feel that the tendency to go off to sleep was associated with their very immobility. However, such a picture is common enough in myotonic patients who have no disturbance of sleep whatsoever. In all four patients the restlessness of their sleep at night was in striking contrast to the vegetative way in which they spent their days, and did not suggest that the excessive sleep was due to any of the accepted endocrine deficiencies. Closely questioned on the matter, the first patient said that his periods of oversleeping occurred usually in the colder weather, while the second patient was more inclined to associate hers with the summer.

The real point of interest lies in whether this hypersomnia is due to a primary disturbance of the part of the central nervous system concerned with sleep. or whether it is in some way secondary to the myotonic state. Curious narcoleptic states, and disturbances of sleep are not uncommon in severe myopathies where there is gross affection of the respiratory musculature. They have been attributed to slowly developing biochemical changes consequent upon the chronic failure of lung ventilation. Such a mechanism, even if true of some myopathies, clearly does not obtain here, for all four patients had been known to be unusually prone to sleepiness since early childhood and certainly before any weakness was apparent. Another bare possibility, suggested by the patients' immobility in bed, that the myotonia gripped them and held them still so that like Pavlov's confined dog they went to sleep, may be discounted because of the restlessness of their sleep.

The likelihood seems to be, considering the histories of the four patients with their resemblances and their accounts of sleepiness going back to childhood, that the disturbance is due to some innate change in the central nervous system. It is yet another of the extramuscular disturbances to be found in this curious disease.

\section{Summary}

Four patients are reported in whom somnolence and hypersomnia were associated with dystrophia myotonica.

We are grateful to Sir Russell Brain, Dr. P. H. Sandifer, and R. A. Henson for permission to describe cases under their care.

\section{REFERENCES}

Rohrer, K. (1916). Dtsch. Z. Nervenheilk., 55, 242.

Thomasen, E. (1948). Myotonia. Universitetsforlaget i Aarhus, Denmark. 